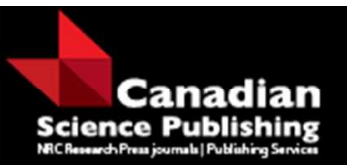

Canadian Journal of Forest Research Revue canadienne de recherche forestière

\title{
Optimality of continuous cover vs. clearcut regimes in managing forest resources
}

\begin{tabular}{|r|l|}
\hline Journal: & Canadian Journal of Forest Research \\
\hline Manuscript ID & cjfr-2015-0474.R2 \\
\hline Manuscript Type: & Article \\
\hline Date Submitted by the Author: & $16-$ Mar-2016 \\
\hline Complete List of Authors: & $\begin{array}{l}\text { Tahvonen, Olli; University of Helsinki, } \\
\text { Rämö, Janne; University of Helsinki, Department of Forest Sciences }\end{array}$ \\
\hline Keyword: & $\begin{array}{l}\text { continuous cover forestry, uneven-aged forestry, even-aged forestry, } \\
\text { optimal rotation, forest economics }\end{array}$ \\
\hline
\end{tabular}

\section{SCHOLARONE ${ }^{\text {m }}$ \\ Manuscripts}


Optimality of continuous cover vs. clearcut regimes in managing forest resources

Olli Tahvonen (corresponding author)

Janne Rämö

University of Helsinki

Department of Forest Sciences

Latokartanonkaari 7, 00014 University of Helsinki

olli.tahvonen@,helsinki.fi,

janne.ramo@helsinki.fi 


\title{
Optimality of continuous cover vs. clearcut regimes in managing forest
} resources

\begin{abstract}
Optimization models on continuous cover forestry are complicated and are typically incompatible with rotation models. This dichotomy is theoretically unsatisfactory and makes the choice between clearcuts and continuous cover forestry vague. We present a theoretically sound and empirically detailed generalized setup with optimal clearcut regime (or even-aged management) and optimal continuous cover regime (or unevenaged management) as special cases. It includes a size-structured growth model, variable and fixed harvesting costs and allows for the completely flexible optimization of harvest timing in both regimes. Flexible harvest timing becomes essential when optimizing the transition from clearcut regimes toward continuous cover forestry. The model is applied to Norway spruce (Picea abies) and solved as a dynamic mixed-integer problem. Low or moderate site productivity, an interest rate above $2 \%$ and high artificial regeneration cost support the optimality of continuous cover forestry. In its most general form, the optimal clearcut regime does not exist when the continuous cover regime is globally optimal, and when it exists, the rotation period lengthens with interest rate. The optimal choice between forest management regimes may depend on the initial stand state and whether the naturally regenerated seedlings are utilized in solutions with clearcuts. Maximizing sustainable yield favors clearcuts.
\end{abstract}

Keywords: continuous cover forestry, uneven-aged forestry, even-aged forestry, optimal harvesting, optimal rotation, forest economics 


\section{Introduction}

Even-aged management has proved an efficient method for producing high amounts of timber and its economic characteristics can be explained by the optimal rotation model that is empirically applicable and taken to be theoretically sound. In advanced economic models the objective is to maximize the present value of net timber revenues by optimizing regeneration, timing, number and type of thinning in addition to the rotation period. Economic studies of stand-level forest management have concentrated on developing these models albeit they describe planted forests ${ }^{1}$ that represent $7 \%$ of the world's forests (Payn et al. 2015).

Uneven-aged or continuous cover forestry ${ }^{2}(\mathrm{CCF})$ has been observed to offer several favorable features such as higher resistance against natural hazards (insects, storm damage), better adaptation potential to climate change (Gauthier et al. 2015) and higher environmental, esthetic, recreational and cultural values (O'Hara 2014). The main drawback of CCF is reported to be low timber output and related economic losses. For example, the Swedish forest agency has investigated suitable principles for compensating forest owners who may switch to CCF with lower private profitability but higher socially favorable features (Cedergren 2008). However, the level of such compensations is difficult to anticipate due to the complexity in comparing the outputs of CCF and forestry based on clearcuts. Our study aims to develop the continuous cover management model and among other things it offers a setup for theoretically sound profitability comparisons between the management alternatives.

Economic models for optimizing the management of CCF are less established compared to models on forestry based on clearcuts, with the consequence that the latter

\footnotetext{
${ }^{1} \mathrm{Planted} / \mathrm{seeded}$ trees are expected to constitute more than 50 percent of the growing stock at maturity. ${ }^{2}$ We apply the terminology suggestion by Pommerening and Murphy (2004) and prefer continuous cover forestry $(\mathrm{CCF})$ or continuous cover regime as synonyms for uneven-aged forestry. For even-aged forestry we prefer the term clearcut regime or forestry based on clearcuts.
} 
are often also applied to the management of more natural heterogeneous forests. The problem in developing models on CCF is their complexity. While optimal rotation models include a single tree cohort (with perhaps a heterogeneous size structure) and some finite rotation length that is repeated as identical, a general model for continuous cover management includes regeneration dynamics, multiple tree cohorts and size classes and no obvious length for a finite time horizon. The research on CCF includes several suggestions for simplifying the analysis to an essentially static model with economically unclear objective functions (for discussion see Getz and Haight 1989, Rämö and Tahvonen 2014). The understanding of how to optimize CCF is still far from complete in both research and practical operations. A further implication is that it is difficult to know what the actual economic losses are if CCF is applied when desirable and silviculturally viable for certain reasons. In contrast to the dichotomous division into either CCF or clearcut models, our study develops and applies a generalized empirically detailed model that simultaneously includes both alternatives as potentially optimal management choices.

Hanewinkel (2002) reviewed studies comparing the financial outcomes of CCF and clearcut regimes and found serious problems in both empirical experiments and modelling applications. The main problem of the latter is that the management alternatives are specified more or less arbitrarily. A valid comparison should instead be based on comparing solutions that are optimal for both management alternatives. Our study takes a further step toward this direction by applying a generalized model that simultaneously covers both options. This setup is necessary for sound profitability comparisons e.g. in boreal forests where forestry is based on native tree species that also regenerate naturally. However, the setup can be easily extended to describe the choice between naturally regenerating continuous cover and planted forests with more distinct differences. This line of analysis has been initialized by Haight and Monserud (1990) and 
Tahvonen et al. (2010). Their approach is first to apply the rotation model to obtain optimal clearcut regimes and the related maximized bare land value. The next step is to specify a dynamic model for CCF with an initial stand state and an option to clearcut and switch to clearcut regime (at any period). If such a regime switch is never optimal, CCF is financially optimal and vice versa. Continuous cover management turned out to be optimal for mixed Rocky Mountains conifer stands in Haight and Monserud (1990) and for Norway spruce (Picea abies) in Fennoscandia in Tahvonen et al. (2010) and Tahvonen (2011), albeit in the latter case the result depends on site productivity and economic parameters. The dominant management regime in western US and the Nordic countries has been and still is the clearcut regime, and these results have been surprising and call for further validation and development in both the overall modelling setup and in various details.

The first problem in the existing studies is in the use of the optimal rotation model where a clearcut is required by construction. A generalized model should include both artificial and natural regeneration with the consequence that instead of a clearcut it may be optimal to continue thinning (or selection cuttings) forever, i.e. to apply CCF. As shown theoretically in Tahvonen $(2015 \mathrm{a}, \mathrm{b})$ the optimal finite rotation period (nor the related bare land value) does not exist in such cases. Thus the procedure of first specifying maximized bare land value for the clearcut regime and then optimizing a possible switch to this regime is valid only if the clearcuts happen to be optimal. A further problem arises because with initial states unfavorable to $\mathrm{CCF}$, it may be optimal to clearcut once and then transform the stand toward an uneven-aged structure (Tahvonen 2015a). In addition, even the long-run optimality of the management regime may depend on the initial stand state. These possibilities cannot be handled coherently by the setup, where the problem is to optimize a possible switch to clearcut regime only. 
Both Haight and Monserud (1990) and Tahvonen et al. (2010) assume some constant period between harvests, although in the presence of fixed harvesting costs, the period between harvests depends on the initial stand state and should be allowed to vary. Even the optimal steady state harvesting cycle, stand structure and harvest cannot be found without simultaneously solving the optimal transition path. The simplification of a fixed harvesting cycle is particularly problematic when the initial stand state is far from the long-run steady state. Thus, without an optimized flexible harvesting cycle, it is not possible to obtain sound results for optimal steady states, nor optimal transitions from clearcuts to CCF. Optimizing harvest timing leads to a demanding infinite horizon mixedinteger problem, which, almost without exceptions, is circumvented in stand-level optimization studies.

Our study includes the possibility that starting from bare land may yield an infinitely long rotation as the optimal solution, i.e. it may be optimal to maintain a continuous forest cover and apply only selection cuttings. If finite rotation turns out to be optimal when started from bare land, it is logical to study whether the same regime is optimal from other initial states as well instead of maintaining continuous forest cover. This setup avoids the inconsistency problems of earlier studies. Our model additionally includes a detailed empirical harvesting cost model with variable and fixed harvesting costs, and we optimize harvest timing allowing it to be completely flexible. Stand growth is given by an empirically estimated matrix transition model that is different than those in earlier studies comparing the management regimes. Optimal solutions are computed for various site productivities, interest rates and artificial regeneration costs. Given the achievements in the theoretical model structure and in various details such as optimized flexible harvest timing, our study is able to present a more coherent and well-grounded picture of the choice between $\mathrm{CCF}$ and clearcuts compared to those in the earlier studies. 
2. The size-structured optimization problem for varying harvesting cycles

Let $x_{s t}, s=1, \ldots, n, t=t_{0}, t_{0}+1, \ldots, T$, denote the number of trees in size class $s$ at the beginning of period $t$; assume $T \in\left[t_{0}, \infty\right)$ and denote the stand state by $\mathbf{x}_{t}=\left(x_{1 t}, x_{2 t}, \ldots, x_{n t}\right)$. The fractions $0 \leq \alpha_{s}\left(\mathbf{x}_{t}\right) \leq 1, s=1, \ldots, n-1$ of trees move to the next size class at the end of each period (before harvest), and the fractions $0 \leq \mu_{s}\left(\mathbf{x}_{t}\right) \leq 1, s=1, \ldots, n$ of trees die. Thus, the fraction $1-\alpha_{s}\left(\mathbf{x}_{t}\right)-\mu_{s}\left(\mathbf{x}_{t}\right) \geq 0$ of trees remains in their current size class. Natural regeneration depends on stand state $\mathbf{x}_{t}$ and is given by function $\phi$. The variables $h_{s t}, s=1, \ldots, n$, denote the trees harvested at the end of each period and let $\mathbf{h}_{t}=\left(h_{1 t}, h_{2 t}, \ldots h_{n t}\right)$. Let $w \geq 0$ denote the cost from artificial regeneration. Revenues $R\left(\mathbf{h}_{t}\right)$ from thinnings, and $R\left(\mathbf{x}_{T}\right)$ from clearcuts depend on the number and size of trees harvested. Harvesting costs are given separately for thinning and clearcuts, by $C_{t h}\left(\mathbf{h}_{t}\right)$ and $C_{c l}\left(\mathbf{x}_{T}\right)$. Let $b^{\Delta}=1 /(1+r)$ denote the discount factor, where $r$ is the interest rate (p.a.) and $\Delta$ the period length. The harvesting cost includes fixed $\operatorname{cost} C_{f}$. It may thus not be optimal to harvest the stand during every period. This is taken into account by the binary variables $\delta_{t}: \square \in[0,1], t=t_{0}, t_{0}+1, \ldots$ and by the Boolean operator $h_{t}=\delta_{t} h_{t}$. When the choice is $\delta_{t}=1$, the levels of $h_{s t} \geq 0, s=1, \ldots, n$ can be freely optimized, and when $\delta_{t}=0$, the only admissible choice is $h_{s t}=0, s=1, \ldots, n$. The problem of optimizing harvests over an infinite horizon can now be given as,

$$
J\left(\mathbf{x}_{t_{0}}, T\right)=\max _{\left\{h_{s}, \delta_{t}, t=t_{0}, \ldots, T, T\right\}} \frac{-w+\sum_{t=t_{0}}^{T-1}\left[R\left(\mathbf{h}_{t}\right)-C_{t h}\left(\mathbf{h}_{t}\right)-\delta_{t} C_{f}\right] b^{\Delta(t+1)}+\left[R\left(\mathbf{x}_{T}\right)-C_{c l}\left(\mathbf{x}_{T}\right)-\delta_{T} C_{f}\right] b^{\Delta(T+1)}}{1-b^{\Delta(T+1)}}
$$

subject to,

$$
x_{1, t+1}=\phi\left(\mathbf{x}_{t}\right)+\left[1-\alpha_{1}\left(\mathbf{x}_{t}\right)-\mu_{1}\left(\mathbf{x}_{t}\right)\right] x_{1 t}-h_{1 t}, t=t_{0}, \ldots, T,
$$




$$
x_{s+1, t+1}=\alpha_{s}\left(\mathbf{x}_{t}\right) x_{s t}+\left[1-\alpha_{s+1}\left(\mathbf{x}_{t}\right)-\mu_{s+1}\left(\mathbf{x}_{t}\right)\right] x_{s+1, t}-h_{s+1, t}, s=1, \ldots, n-1, t=t_{0}, \ldots, T,
$$

$$
h_{s t}=\delta_{t} h_{s t}, s=1, \ldots, n, t=t_{0}, \ldots, T
$$

$$
\mathbf{x}_{t_{0}} \text {, given, }
$$

and the conditions $x_{s t} \geq 0, \quad h_{s t} \geq 0, t=t_{0}, \ldots, T, s=1, \ldots, n$.

This specification resembles the optimal rotation model but with one essential difference. When the choice is some finite $T$, clearcutting occurs at the end of period $T$ and the solution is a finite rotation and the clearcut regime. However, it is possible that the optimal value of $T$ becomes infinite, implying that only thinnings or selection cuttings occur but no clearcuts, and that it is optimal to maintain a continuous forest cover. The choice of the optimal rotation period (including the possibility that it may be infinitely long) thus determines the choice between continuous cover solutions and solutions with clearcuts. It may be expected that solutions with $T=\infty$, i.e. continuous cover solutions, may represent the optimal choice if natural regeneration is competitive with respect to costly artificial regeneration.

Given the value function $J\left(\mathbf{x}_{t_{0}}, T\right)$ for (1)-(5) but initial states $\hat{\mathbf{x}}_{t_{0}}$ that do not represent just regenerated bare land the objective function is

$$
J\left(\hat{\mathbf{x}}_{t_{0}}, T_{1}\right)=\max _{\left\{h_{t}, \delta_{t}, t t_{0}, \ldots, T_{1}, T_{1}\right\}} \sum_{=_{t_{0}}}^{T_{1}-1}\left[R\left(\mathbf{h}_{t}\right)-C_{t h}\left(\mathbf{h}_{t}\right)-\delta_{t} C_{f}\right] b^{\Delta(t+1)}+\left[R\left(\mathbf{x}_{T_{1}}\right)-C_{c l}\left(\mathbf{x}_{T_{1}}\right)-\delta_{T_{1}} C_{f}+J\left(\mathbf{x}_{t_{0}}, T\right)\right] b^{\Delta\left(T_{1}+1\right)}
$$

where $T_{1} \in\left[t_{0}, \infty\right)$. Note that albeit the optimal $T$ for (1)-(5) would be finite, the clearcut regime may not represent the optimal long-run solution when the initial state includes trees in larger diameter classes. In these cases the optimal $T_{1}$ for (6) becomes infinite. If the optimal $T$ for (1)-(5) is infinite, it may follow that the optimal $T_{1}$ in (6) is infinite as well and the terminal valuation function $\left[R(\square)-C_{c l}(\square)-\delta_{T_{1}} C_{f}+J(\square)\right] b^{\Delta\left(T_{1}+1\right)}$ in (6) 
vanishes. However, it is also possible that the initial state $\hat{\mathbf{x}}_{t_{0}}$ is somehow unfavourable for continuous cover solutions and that it becomes optimal to clearcut once, perhaps immediately at $t_{0}$. In this case there are no net revenues from thinning in (6) and the present value net revenues are given by the terminal valuation function only. ${ }^{3}$

Bollandsås et al. (2008) use Norwegian National Forest Inventory data and estimate uneven-aged models for most common Nordic tree species. Their model can be expected to be suitable for all of Fennoscandia (Rämö and Tahvonen 2014). In our study, we use their results for Norway spruce. In their model, the two measures for stand density are the total stand basal area $B\left(\mathbf{x}_{t}\right)\left(m^{2} h a^{-1}\right)$ and the basal area for trees larger than trees in the given size class $B_{s}\left(\mathbf{x}_{t}\right), s=1, \ldots, n-1\left(m^{2} h a^{-1}\right)$. Denoting the basal area per tree in size class $s$ by $\gamma_{s}, s=1, \ldots, n$ (Table 1 ), these density measures can be given as, $B\left(\mathbf{x}_{t}\right)=\sum_{s=1}^{n} \gamma_{s} x_{s t}$ and $B_{s}\left(\mathbf{x}_{t}\right)=\sum_{i=s+1}^{n} \gamma_{i} x_{i t}, s=1, \ldots, n-1$

In Bollandsås et al. (2008) regeneration depends negatively on the total basal area and positively on site index $S I$ and is given per five years as $\phi\left(\mathbf{x}_{t}\right)=\frac{54.5633 S I^{0.368}\left[B\left(\mathbf{x}_{t}\right)+\varepsilon\right]^{-0.157}}{1+e^{0.391-0.066 S I+0.018 B\left(\mathbf{x}_{t}\right)}}$.

Note that $\phi$ is strictly convex in $\mathbf{x}$, implying non-convexities. Regeneration with zero basal area is possible because trees have efficient means of dispersal. In Bollandsås et al. (2008), $\varepsilon=0$ and $\phi\left(\mathbf{x}_{t}\right) \rightarrow \infty$ as $\mathbf{x}_{t} \rightarrow 0$. This feature is unwarranted and based on Wikberg (2004) and Pukkala et al. (2009) we set $\varepsilon=0.741$ implying $\phi(0)=100$. This modification prevents obtaining an infinite number or trees and yields less than one tree decrease in ingrowth per year when the basal area is above $2 \mathrm{~m}^{2}$.

\footnotetext{
${ }^{3}$ The existence of these possibilities and the dependence of the optimal solution on the initial state is shown theoretically in Tahvonen (2015a).
} 
The tree fractions that move to the next size class (per five years) are given by

$\alpha_{s}\left(\mathbf{x}_{t}\right)=0.02\left(17.839+0.048 d_{s}-11.585 \times 10^{-5} d_{s}^{2}-0.341 B_{s}\left(\mathbf{x}_{t}\right)+0.906 S I-0.024 B\left(\mathbf{x}_{t}\right)-0.268 L\right)$,

where $s=1, \ldots, n-1, d_{s}, s=1, \ldots, n$ are tree diameters ( $\mathrm{m} m$ at breast height, Table 1$), S I$ is

site growth index and $L$ is latitude. We set $L=61.9^{\circ} N$. For the site index, we apply $S I=11 m, 15 m$ or $17 m$, where e.g. $S I=11 m$ refers to the length (in $m$ ) of 100 dominant trees at 40 years. The site index refers to low-, average-, and high-growth conditions (and corresponds to tree lengths of 21,24 , and 27 meters at 100 years). The fractions of dying trees (per five years) equal

$\mu_{s}\left(\mathbf{x}_{t}\right)=\left[1+e^{2.492+0.02 d_{s}-3.2 \times 10^{-5} d_{s}^{2}-0.031 B\left(x_{t}\right)}\right]^{-1}, s=1, \ldots, n$.

To compute tree volumes per size class (Table 1) we apply the tree height model from Pukkala et al. (2009). According to their empirical model, the tree heights and volumes as a function of diameter (at the height of $130 \mathrm{~cm}$ ) are equal for site indices $15 \mathrm{~m}$ and $17 \mathrm{~m}$ (but not for site index 11m). Applying Heinonen (1994), the volumes of small diameter $\operatorname{logs} v_{1 s}, s=1, \ldots, n$ (pulpwood) and sawtimber $v_{2 s}, s=1, \ldots, n$ are as shown in Table 1 When the initial state is bare land, the optimization begins after the trees have entered size class one. This takes 15, 20 or 25 years depending on site productivity. The initial states are $\mathbf{x}_{t_{0}}=1750,0, \ldots, 0$ or $\mathbf{x}_{t_{0}}=2250,0, \ldots, 0$, which are in line with silvicultural recommendations and optimal densities obtained in earlier studies (Niinimäki et al. 2011).

The per period gross revenues are specified as

$R\left(\mathbf{h}_{t}\right)=\sum_{s=1}^{n} h_{s t}\left(v_{1 s} p_{1}+v_{2 s} p_{2}\right), t=0,1, \ldots$

where $p_{1}$ and $p_{2}$ are the (roadside) prices $(€)$ of small-diameter logs and sawtimber, respectively. Denote $v_{s}=v_{1 s}+v_{2 s}$. In empirical models by Nurminen et al. (2006) the 
variable harvesting costs (cutting and hauling) depend on the number and volumes of trees cut and are given separately for thinning and clearcuts as

(7) $C_{i}=C_{i 0} C_{i 1} \sum_{s=1}^{n} h_{s t}\left(C_{i 2}+C_{i 3} v_{s}-C_{i 4} v_{s}^{2}\right)+C_{i 5}\left[C_{i 6} \sum_{s=1}^{n} h_{s t} v_{s}+C_{i 7}\left(\sum_{s=1}^{n} h_{s t} v_{s}\right)^{0.7}\right], i=t h, c l$,

where $C_{i 0}$ is the per minute cutting cost $(€)$ and its coefficient $C_{i 1}(\square)$ the time spent (in minutes) cutting one tree (and moving the machinery to the next), and $C_{i 5}$ and its coefficient $[\square]$ are the cost and time spent for hauling, respectively. The parameter values for $C_{i j}, i=t h, c l, j=0, \ldots, 7$ ( $t$ th=thinning, $c l=$ clearcut $)$ are given in Table 2 .

These functions are based on the performance of modern harvesters, and are estimated from data obtained from detailed empirical experiments (Nurminen et al. 2008). The parameter $C_{t h 1}=1.150$ in the cutting cost element for thinning takes into account that cutting one tree and moving to the next one is more costly in (continuous cover) thinning compared with clearcuts (Surakka and Siren 2007). Hauling in thinning is additionally more time-consuming compared with clearcuts. The properties of these functions are described in Figure 1. Variable harvesting costs (cutting plus hauling cost) increase almost linearly with harvested volume (per operation) when the size of the harvested trees is fixed (Figure 1a). However, it is less costly per $m^{3}$ to harvest larger trees. Harvesting a tree in the clearcut is less costly than harvesting similar trees in continuous cover operations. Figure $1 \mathrm{~b}$ shows that harvesting costs per $\mathrm{m}^{3}$ depend greatly on tree volume (and decrease slightly with the number of trees harvested). The roadside prices for sawtimber and pulp are $€ 58.44$ and $€ 34.07$ respectively, and the fixed cost equals $€ 500$. 


\section{Computational methods}

The variables $\delta_{t}: \square \in[0,1], t=t_{0}, t_{0}+1, \ldots$ are integers but $h_{s t}, s=1, \ldots, n, t=t_{0}, t_{0}+1, \ldots$ are continuous, implying that the task is to solve a mixed-integer nonlinear programming problem. We apply bilevel optimization (Colson et al. 2007) where optimizing the binary variables is taken as the upper-level problem and optimizing the continuous variables as the lower-level problem. Given any vector of the binary variables, the lower-level problem is computed applying gradient-based methods and the Knitro optimization software version 9.1 (Byrd et al. 2006). The maximized objective value of this problem forms the objective value given any vector of harvest timing binaries. They are optimized using a random restart hill-climbing algorithm or simply by computing the lower-level problem for all harvest timing alternatives. To restrict the solution space we assume that there will be at least one period between harvests and that when the initial state is bare land no harvest occurs during the first three periods. Problem (1)-(5) is solved by lengthening the horizon and repeating the optimization for each horizon length. If the objective function obtains a maximum with some $T \in[40,180)$ years, the optimal rotation is finite. To obtain the infinite horizon solution, the horizon is lengthened until further lengthening no longer changes the solution towards a steady state with some stabilized stand structure and time period between harvests. Potential non-convexities are handled by applying multiple randomly chosen initial points for the search algorithm. Applying efficient parallel computation (Intel (R) Xeon (R) E5-2643 v3@3.40GHZ, 24 logical processors), the optimal harvest intensity and timing is found within 2-30 hours. 


\section{Results}

\section{Classic Faustmann clearcut solutions}

The classic and still most common approach to stand-level optimization is the model where rotation is the only optimized variable (cf. Samuelson 1976). Specification (1)-(5) defines this case if we set $\delta_{t}=0, t \in\left[t_{0}, T-1\right], \delta_{T}=1$, implying that the stands can be harvested only at clearcuts. The marginal growth in Figure 2a equals average growth when stand age is 50-75 years (dotted lines) revealing the maximum sustainable yield (MSY) rotation, whereas the economic rotation with zero interest rate and regeneration cost is somewhat longer (Figure $2 \mathrm{~b}$ ).

The diameter of harvested trees at the clearcuts varies between $75-475 \mathrm{~mm}$. Given a $2 \%$ interest rate, $S I=17 \mathrm{~m}, w=0$, and $x_{10}=1750$, the economically optimal rotation period is 55 years, the bare land value is $€ 9680$, the net clearcut revenues $€ 19086$, total harvesting cost $€ 2730$, the average volume of harvested tree $0.26 \mathrm{~m}^{3}$, the harvesting cost per $m^{3} € 6.3$ ( $€ 1.6$ per tree), and $70 \%$ of the yield is sawtimber.

The average annual yield and bare land value increase with site productivity and decrease with interest rate (Table 3). A higher interest rate implies shorter rotation, lower bare land value and average yield, except in a case where the rotation period is above the MSY rotation (site index $11 \mathrm{~m}$ ).

These results are strictly in line with the classic rotation model. The results are additionally similar to earlier, (more) detailed empirical results (Niinimäki et al. 2012). Given a site index close to $S I=17 \mathrm{~m}$, interest rate between $1 \%$ and $4 \%$ and no thinning they obtain optimal rotations between 69 and 53 years. 
Optimizing the management regime

Figure 3 shows the two qualitatively different outcomes when the time horizon in the objective function (1) is increased and the problem is solved without any constraints on harvests. In Figure 3a, the value of bare land reaches the maximum (€5677) when the rotation period is 90 years and decreases thereafter. The continuous cover solution yields a slightly lower bare land value (dashed line, €5638). In this case the optimal choice is finite rotation. Note that artificial regeneration is assumed to cause no cost, the interest rate is $3 \%$ and the number of trees in the smallest size class 15 years after the clearcut is $1750 h a^{-1}$. However, given a $€ 1000 h a^{-1}$ regeneration cost, the bare land value is higher the longer the rotation period and the bare land value asymptotically approaches the continuous cover outcome from below (Figure 3b). Thus the continuous cover solution is globally optimal and no optimal finite rotation exists. Accordingly, when an optimal clearcut solution exists, the continuous cover solution represents a local minimum with respect to the choice of the rotation period.

\section{Optimal continuous cover solutions}

Figures $4(a-d)$ show optimal continuous cover solutions when the interest rate is $1-4 \%$ and $S I=17 \mathrm{~m}$. Given regeneration cost equal to $€ 2000 \mathrm{ha}^{-1}$ these solutions are globally optimal when the interest rate is $3 \%$ or $4 \%$. The stand is optimally thinned for the first time at 45 years of age if the interest rate is $1-2 \%$ and at 40 years of age if the interest rate is $3-4 \%$. Thereafter, the (optimized) time between harvests converges toward a steadystate cycle that varies between 15 and 25 years depending on the interest rate. The classic optimal rotation model suggests that the steady-state harvesting cycle should shorten with interest rate. However, the cycle is 20 years for interest rates $1 \%, 2 \%$, and $4 \%$, but 15 years when the interest rate is $3 \%$. To interpret this, note that the steady-state volume and 
number of trees are lower the higher the interest rate (Figures 4a-d). The volume varies between $230 \mathrm{~m}^{3} \mathrm{ha}^{-1}$ and $130 \mathrm{~m}^{3} \mathrm{ha}^{-1}$ if the interest rate is $1 \%$ and between $130 \mathrm{~m}^{3} \mathrm{ha}^{-1}$ and $40 m^{3} h a^{-1}$ if the interest rate is $4 \%$. The volume depends on the number and size of harvested trees. The size of trees decreases with interest rate so that when it is $1 \%$, the diameter of harvested trees is $325-475 \mathrm{~mm}$, and when the interest rate is $4 \%$, the diameter is $225-375 \mathrm{~mm}$. Thus, the capital tied up in trees is liquidated by intensified cuttings and lower stand volume implying that postponing the next harvest yields lower interest costs. This explains why the harvesting cycle may lengthen with higher interest rate.

Figure 5 shows the stand structure over the steady-state cycle when the interest rate is $2 \%$ and $\mathrm{SI}=17$. The harvesting cycle is four periods and trees are harvested from four size classes. Regeneration (not shown) varies between 11 and 13 per year over the steady-state cycle. Given any parameter constellation, trees are completely harvested from $n$ size classes if the length of the harvesting cycle is $n$. The steady-state yield per harvest equals $127 \mathrm{~m}^{3} \mathrm{ha}^{-1}$, implying that the average annual yield is $6.3 \mathrm{~m}^{3}$. Of this, $91 \%$ is sawtimber and the rest pulpwood. Gross revenues per harvest equal $€ 7100$ and harvesting costs equal $€ 1200$. Total and variable harvesting costs per $m^{3}$ are $€ 9.5$ and $€ 5.5$, respectively. The volume of an average harvested tree at the steady state is $0.66 \mathrm{~m}^{3}$.

If continuous cover solutions are compared with solutions based on clearcuts only (Figure 2, Table 3), they yield a higher bare land value at any interest rate, site index, initial number of seedlings and regeneration cost combinations. For example, given the case in Figure $4 \mathrm{~b}\left(S I=17 m, r=0.02, w=0, x_{10}=1750\right)$, the continuous cover solution yields a bare land value equal to $€ 16780$ and the clearcut solution without thinning yields $€ 9676$. Given the continuous cover solution, the average (steady state) size of a harvested tree is $0.66 \mathrm{~m}^{3}$, whereas in clearcuts it is $0.26 \mathrm{~m}^{3}$. Continuous cover solution outperforms 
the classic clearcut solution because it is optimal to liquidate the capital tied up in the largest trees sooner than at the moment of an optimized clearcut. Second, thinning only the largest trees implies a higher share of valuable sawtimber per harvested tree and higher stumpage value (€37 vs. $€ 11$ ), although harvesting cost per cubic metre is higher (€9 vs. €6). Note that the continuous cover solution seems to outperform the pure clearcut solution even with zero cost of artificial regeneration.

\section{Optimal clearcut solutions with optimized thinning}

Given zero regeneration costs, optimal clearcut solutions exist and are globally optimal e.g. for site index $17 \mathrm{~m}$, interest rate $1-4 \%$ and $x_{10}=1750$. Figures $6 a-d$ show how the stand volume and number of trees develop over the rotation. In the classic rotation model, shortening the rotation length is the only possibility for liquidating the capital tied up in trees. Here it is additionally possible to speed up thinning, and increase thinning intensity and number. This together with natural regeneration implies that the effect of higher interest rate on rotation length is minor and instead the stand volume clearly decreases with interest rates. When the interest rate increases from $3 \%$ to $4 \%$, the rotation period lengthens and the number of thinnings increases from three to four implying lower stand volume with higher interest rate. The size of thinned trees additionally decreases and is $275-375 \mathrm{~mm}$ when $\mathrm{r}=0.01$ and $225-325 \mathrm{~mm}$ when $\mathrm{r}=$ 0.04 . The share of sawtimber in cuttings is $85 \%$ when $r=1 \%$ and $76 \%$ when $r=4 \%$, i.e. clearly lower than under the continuous cover solutions (91\%). Average variable harvesting costs (over all $1-4 \%$-solutions) in thinning operations is $€ 6$ and $€ 6.5$ in clearcuts. This follows because when thinning from above the size of the average harvested tree is much larger in thinnings $\left(0.58 \mathrm{~m}^{3}\right)$ compared with clearcuts $\left(0.28 \mathrm{~m}^{3}\right)$. Taking into account the fixed harvesting cost, the cost per $m^{3}$ equals $€ 9.4$ in thinning 
operations and $€ 8.7$ in clearcuts. The share of net thinning revenues from bare land value is $86 \%$ when the interest rate is $4 \%$ and $69 \%$ when the interest rate is $1 \%$, demonstrating that neglecting thinning, as in the classic rotation model, is a strong simplification.

\section{Comparing clearcut and continuous cover harvesting}

If the aim is MSY, it is optimal to harvest trees every period after year 40 until the clearcut (Table 4, MSY/CC solutions). The MSY rotation varies between 90 and 135 years and yields an average annual output between $4.8 \mathrm{~m}^{3}$ and $9 \mathrm{~m}^{3}\left(\mathrm{ha}^{-1}\right)$ depending on site productivity. The maximum annual volume output (MSY/CCF) under the continuous cover solution is lower, i.e. $4.3-7.0 \mathrm{~m}^{3}$.

Compared with MSY/CC, economically optimal solutions lead to longer rotation periods, which are additionally longer with higher interest rate. Given a regeneration cost of $€ 1000$ per ha and an initial number of trees of 1750 , the continuous harvesting solution is optimal for site indices $11 \mathrm{~m}$ and $15 \mathrm{~m}$ when the interest rate is $2-4 \%$.

Table 5 shows the optimal forest management regime for various interest rates, site indices and regeneration cost levels. The first figure (when it exists) is the bare land value for the (globally) optimal clearcut solution and the second for the optimal continuous cover solution. A low interest rate and regeneration cost and high site quality favor clearcut solutions and vice versa. Clearcut solutions are always optimal when the interest rate is $1 \%$ and the regeneration cost is low or zero. Note that the continuous cover solution is optimal for site indices $11 \mathrm{~m}$ and $15 \mathrm{~m}$ when the interest rate is $4 \%$, even when the regeneration cost is zero.

Table 6 shows that with a higher initial number of trees, the clearcut solution becomes optimal excluding the average and low productivity sites, and higher interest rates and regeneration costs. Observe that the difference is not large and given no 
regeneration cost, a $1 \%$ interest rate and site index $17 \mathrm{~m}$, the continuous cover solution still yields more than $90 \%$ of the maximized bare land value.

\section{Dependence of the optimal solution on the initial state}

Although the continuous cover solution would be the optimal long-run solution, it may be optimal to clearcut at the beginning. This situation occurs if the initial state is unfavourable for continuous harvesting. Assume $S I=11 \mathrm{~m}, \mathrm{r}=3 \%, \quad x_{10}=2250$, $\mathbf{x}_{0}=[0,0,138,99,48,13,1.2,0,0,0,0,0]$ and $w=€ 500$. Excluding the fact that $x_{10}=x_{20}=0$, the state is the beginning-of-period state from the steady-state cycle of a globally optimal continuous cover solution. Applying objective (6) shows that a clearcut at the end of the first period yields €3887. Applying a continuous cover solution thereafter will yield a bare land value of $€ 1969$. Their sum exceeds the outcome of $€ 4968$ that is obtained if a continuous cover solution is applied right from the beginning.

It is equally possible that even when the continuous cover solution is not optimal for bare land as the initial state, it may be optimal if the initial state is closer to the optimal continuous cover steady state. An example of such a case is given in Table 6 where $S I=15 \mathrm{~m}, \mathrm{r}=3 \%$, and a regeneration cost of $€ 1000$ yields equal bare land values for both regimes. However, if initial state is taken from the continuous cover steady state, maximizing (6) as the objective function shows that it is optimal not to clearcut until the regeneration cost falls below $€ 929$. However, with $w<€ 1000$ and the initial state as bare land, the clearcut regime is optimal. Thus, given $€ 929<w<€ 1000$, the optimal solution depends on the initial state and is the continuous cover regime if the initial state is on the continuous cover steady-state cycle, and the clearcut solution if the initial state is bare land. A similar situation results, e.g. when $S I=11 m, r=3 \%$, and $€ 237<w<€ 399$. 


\section{Discussion}

Originated from Adams and Ek (1974), most optimization studies on uneven-aged forestry approach the problem in two steps: first some steady state stand structure is specified and second, a transition path that must reach the steady state within a given time period (O’Hara 2014, p. 132). However, solving the steady state without simultaneously solving the transition path is mathematically correct only with zero interest rate. With a positive interest rate it is not possible to find the optimal steady state independently of the optimal approach path. A steady-state structure is optimal only if an initial deviation from the steady-state harvesting and approaching some other steady state does not yield a higher net present value. With a positive interest rate such a deviation becomes beneficial even when the steady state maximizes the net present value of revenues under the restrictions that the stand structure and harvest must be constant or follow some fixed harvesting cycle. This reasoning is evident in the optimal control theory context, but excluding Getz and Haight (1989, p. 267), the problems of solving the steady state and the transition path separately are seldom noticed in the optimization studies of unevenaged management.

Following Chang (1981) many studies assume that the steady state must be reached in one period, i.e. with one harvest. It is unclear whether this simplification could reveal the optimal steady state for complex multiple state variable models, but surely it cannot yield correct maximized net present value revenues for $\mathrm{CCF}$, or an accurate basis for comparing the economic outcome from different management regimes. In addition, reaching steady state with one harvest is admissible only from a restrictive set of initial states and even when it is admissible the unrestricted dynamic transition takes several periods and must solve the optimal harvest timing problem. 
In his review, Hanewinkel (2002) contrasted the Anglo-American literature and the extensive European tradition on uneven-aged forestry. The former is criticized to yield controversial results. The problem of the latter is neglecting the optimization methods and, as emphasized by Hanewinkel (2002), these studies can then hardly reveal the full potential of uneven-aged management, nor unbiased economic comparisons of different management regimes.

Our study specifies the problem of uneven-aged management in line with the established discrete-time dynamic optimization literature (Blot and Hayek 2014). This leads to specifications where the approach path (transition) is solved simultaneously with the long-run steady-state equilibrium with no ad hoc constraints. Earlier, a somewhat similar type of approach is applied by Getz and Haight (1989) and Haight and Monserud (1990). They study Californian white and red fir forests (Abies concolor, Abies magnifica) and assume equal stumpage prices in both regimes (i.e. no harvesting costs) and a 20 -year exogenous and constant harvesting cycle. In comparing the regimes they first solve an optimal clearcut regime and then compute whether it is optimal, from a given initial state, to clearcut at some future date. CCF is optimal if the clearcut is postponed indefinitely. This procedure comes close to ours but differs by the exclusion of variable and fixed harvesting costs. Additionally, the optimal clearcut regime is specified even when the optimal rotation for the initial phase turns out to be infinite, i.e. the optimal solution is CCF and no optimal clearcut solution actually exist. This implies that their procedure is coherent only if some additional qualitative difference between $\mathrm{CCF}$ and the clearcut regime exists.

Following a similar procedure Tahvonen et al. (2010) assume various initial stand states for Norway spruce and compute whether it is optimal to clearcut (at some optimized date) or to continue with continuous cover. The post-clearcut net revenues 
were specified as a bare land value from studies on pure even-aged forestry (no natural regeneration, regeneration cost $€ 1500$ ). The harvesting cycle was fixed at 15 years (with a fixed harvesting cost component equal to $€ 300$ ). CCF turns out to be optimal given any interest rate above $0.5 \%$. This result can be compared with Table 5 (site index $15 m$ and $17 m$, regeneration cost $€ 1500$ ), where clearcut solutions are optimal given the interest rate is $2 \%$ or lower. One main reason for the better profitability of the clearcut solution here is the inclusion of natural regeneration in solutions with clearcuts. In current Nordic practices, naturally regenerated seedlings are removed before harvest operations as "undergrowth clearing." Excluding natural regeneration in our model by setting $\phi\left(\mathbf{x}_{t}\right)=0$ in (2) (costless undergrowth clearing) yields the result that a continuous cover solution is always optimal when $x_{01}=1750$. With the initial stand density $x_{01}=2250$, we obtain the result that the clearcut solution is optimal for site index $15 \mathrm{~m}$ if the interest rate is $1 \%$ (or below) and regeneration cost is zero, and for site index $17 \mathrm{~m}$ if the interest rate is $1 \%$ (or below) and regeneration cost is $€ 1500$ or lower.

Tahvonen (2011) applies a single tree age- and size-structured model for forest growth. The management alternatives are compared by assuming that the initial state equals the continuous cover steady state just before harvesting and then computing whether it is optimal to clearcut or to maintain continuous forest cover. Recall that compared to bare land this initial state favors continuous cover solutions. The bare land values used in the clearcut solutions are again based on planted stands without natural regeneration. According to the results, the continuous cover solution is optimal excluding the most productive sites and an interest rate of $1 \%$ or below, i.e. even-aged solutions are found somewhat less profitable compared to our results. This suggests that in the case of 
self-regenerating native tree species the utilization of natural regeneration along the rotation is important for the relative profitability of clearcut harvesting regimes. ${ }^{4}$

Our study is based on a more coherent and theoretically sound model compared to earlier literature. In addition we have optimized the period length between harvests with full flexibility and based on detailed harvesting cost specifications. This flexibility is necessary especially when the initial stand state is not close to the long-run uneven-aged steady state, i.e. when the problem is to solve optimal transition from even-aged to uneven-aged forestry. Mathematically, this flexibility is needed even for obtaining the correct long-run steady-state harvest solution and the related stand structure. Theoretically a coherent model structure allows us to show that the optimality of continuous cover vs. clearcut regimes may depend on the initial stand state. In addition, it may be optimal to clearcut a stand at the beginning albeit in the long run it would be optimal to maintain a continuous forest cover.

\section{Conclusions}

Optimizing the choice between continuous cover and clearcut regimes is important from the pure wood production point of view but also because the chosen forest management regime has direct implications for forest biodiversity, and esthetic, recreational and cultural values. The potential of continuous cover management in contributing to these values is emphasized in both research and a more practical context (Puettmann et al. 2015, Cedergren 2008). A similar discussion is actively being debated, related to the threats climate change may cause to forestry and forest environments. According to Gauthier et al. (2015), climate change calls for increasing the adaptation capabilities of

\footnotetext{
${ }^{4}$ In utilizing natural regeneration it is crucial whether small seedlings survive the harvesting operations. In a study on harvesting damage and Norway spruce, Modig et al. (2014) conclude that the "overall level of damage to remaining trees was low" and $4.5 \%$ of trees were damaged, implying that less than $10 \%$ of harvested trees will have between 40- and 50-year-old injuries.
} 
forests by increasing their heterogeneity. Both biodiversity and the threat of climate change call for a major diversification of existing forest economic models that are best suited for planted forests. One main obstacle of this task has been the established understanding among forestry professionals that the alternatives to clearcuts (or evenaged management) are not economically viable. However, as noted by several authors (e.g. Hanewinkel 2002, O’Hara 2014), the economic comparison of forest management regimes is complicated and poorly understood. The reason behind these problems has been the lack of a theoretically sound framework that correctly describes both management regimes and enables their smooth profitability comparisons.

Our study is the first that presents empirically detailed comparisons based on a theoretically coherent and generalized model that simultaneously covers both the continuous cover and clearcut forest management regimes. Our setup has been used to present practically relevant guidelines to private forest owners who are planning to diversify their forest management activities (Sved and Koistinen 2015). Our results suggest that applying more natural forms of forest management may not be overly expensive in the case of boreal Norway spruce; as a matter of fact the reverse seems to be true. The validity of earlier theoretical results, showing that a higher interest rate may imply longer, not shorter, rotations and the optimal management regime to be dependent on the initial stand state, has been demonstrated within empirically relevant parameter values. Among other improvements in model structure and details, producing these results requires solving the optimal timing of harvests; a complicated problem that has been more or less open in continuous cover forest economic models.

Camfeldt et al. (2013) write that the level of ecosystem services is higher in forests with many tree species. Roessiger et al. (2016) develop a three-species matrix transition model and compute the optimal development of a species mixture over time. These 
studies suggest the inclusion of multiple tree species in future studies on continuous cover forestry with optimal harvest timing and on the optimal choice between the management regimes. In Tahvonen and Kallio (2006) it is shown that wood price stochasticity and risk aversion calls for diversifying the age structure in a multiple stand even-aged model. Similar effect will occur if the assumption of perfect capital markets is given up (cf. Tahvonen et al. 2001) in an even-aged model that allows partial clearcuts. We conjecture that these factors would have similar implications if they could be included in the model developed in our study.

Acknowledgements

We thank Jim Wilen, the anonymous referees and associate editor for discussion and suggestions.

\section{References}

Adams, D. M., and Ek, A.R., 1974. Optimizing the management of uneven-aged forest stands. Can. J. For. Res. 4, 274-287.

Bollandsås, O.M., Buongiorno, J., and Gobakken, T., 2008. Predicting the growth of stands of trees of mixed species and size: A matrix model for Norway. Scand. J. For. Res. $23,167-178$.

Blot, J., and Naïla H., 2014. Infinite-Horizon Optimal Control in the Discrete Time Framework. New York: Springer.

Byrd, R.H., Nocedal J. and Waltz, R.A., 2006. KNITRO: An integrated package for nonlinear optimization. In G.di Pillo and M. Roma, editors, Large-Scale Nonlinear Optimization, p. 35-59, Springer.

Chang, S.J., 1981. Determination of the optimal growing stock and cutting cycle for an uneven-aged stand. Forest Sci. 27, 739-744.

Camfeldt, L., Snäll, T., Bagch, R., Jonsson, M., et al. 2013. Higher levels of ecosystem services are found in forests with more tree species. Nature Communications 4, 1340 DOI: $10.1038 /$ ncomms 2328 . 
Cedergren, J. 2008. Kontinuitetsgogar och hyggesfritt skogsbruk. Meddeland 1/2008. Swedish Forest Agency, Jönköping, Sweden (in Swedish).

Colson, B., Marcotte, P., and Savard G., 2007. An overview of bilevel optimization. Annals of Operational Research, 153, 235-256.

Gauthier, S., Bernier, P., Kuuluvainen, T., Shvidenko, A.Z., Schepaschenko, D.G., 2015. Boreal forest health and global change. Science. 21 August 2015.

Getz, W.M., and Haight, R.M., 1989. Population harvesting: demographic models for fish, forest and animal resources. New Jersey: Princeton University Press.

Haight, R.G. and Monserud, R.A., 1990. Optimizing any-aged management of mixedspecies stands II: Effects of decision criteria. For. Sci. 36, 125-144.

Hanewinkel, M. 2002. Comparing economic investigations of even-aged and unevenaged silvicultural systems: a critical analysys of diffrent methods. Forestry 75, 473-481.

Heinonen, J., 1994. Koealojen puu- ja puustotunnusten laskentaohjelma KPL. Käyttöohje. Reseach Reports. Finnish Forest Research Institute 504(In Finnish).

Modig, E., Magnusson, B., Valinger, E., Cedergren, J. and Lundqvist, L., 2012. Damage to residual stand caused by mechanized selection harvest in uneven-aged Picea abies dominated stands. Silva Fennica 46, 267-274.

Niinimäki, S., Tahvonen, O. and Mäkelä, A., 2012. Applying a process based model in Norway spruce management. For. Ecol. and Manage. 265, 102-115.

Nurminen, T., Korpunen, H. and Uusitalo, J., 2006. Time consumption analysis of the mechanized cut-to-length harvesting system. Silva Fennica 40, 335-363.

O’Hara, K. 2014. Multiaged silviculture. Oxford University Press, Oxford.

Payn, T., Carnus, J-M., Freer-Smith, P., Kimberley, M., Kollert, W., Liu, S., Orazio, C., Rodriguez, L., Silva, L.N. and Wingfield, M., 2015. Changes in planted forests and future implications. For. Ecol. and Manage. 362, 57-67.

Pommerening, A. and S.T. Murphy. 2004. A review of the history, definitions and methods of continuous cover forestry with special attention to afforestation and restocking. Forestry 77 : 27-44.

Puettmann, K.J., Scott, M.W., Baker, Pablo J., Donoso, P., Drössler, L., Amente, G., Harvey, B.D., Knoke, T., Lu, Y., Nocentini, S. Putz, F. E., Yoshida, T. and Bauhus, J. 2015. Silvicultural alternatives to conventional even-aged forest management - what limits global adoption? Forest Ecosystems 2(8): 2-16.

Pukkala, T., Lähde, E., and Laiho, O., 2009. Growth and yield models for uneven-sized forest stands in Finland. For. Ecol. and Manage. 258, 207-216. 
Roessiger, J., Ficko, A. Clasen, C., Griess, V.C. and Knoke, T., 2016. Variability in growth of trees in uneven-aged stands displays the need for optimizing diversified harvest diameters. Eur J Forest Res DOI 10.1007/s10342-015-0935-6.

Rämö, J. and Tahvonen, O., 2014. Economics of harvesting uneven-aged forest stands in Fennoscandia. Scan. J. of For. Res. 29, 777-792.

Rämö, J. and Tahvonen, O., 2015: Economics of harvesting boreal uneven-aged mixedspecies forests. Can. J. For. Res., 2015, 1102-1112.

Samuelson, P., 1976. Economics of forestry in an evolving society. Econ. Inquiry 14, 466-492.

Sved, J. and Koistinen, A. 2015. Silvicultural recommendations to economically viable forestry: a practical guide. (In Finnish) Tapio, Helsinki. (http://tapio.fi/wpcontent/uploads/2015/09/MHS_Kannattava_metsatalous_201500814.pdf).

Surakka, H. and Sirén, M., 2007. Poimintahakkuiden puunkorjuun nykytietämys ja tutkimustarpeet (in Finnish). Metsätieteen aikakauskirja 4/2007, 373-390.

Tahvonen, O., 2011. Optimal structure and development of uneven-aged Norway spruce forests. Can. J. For. Res. 41, 2389-2402.

Tahvonen, O., 2015a. Economics of naturally regenerating heterogeneous forests. J. of the Association of Environmental and Resource Economists. 2, 309-337.

Tahvonen, O., 2015b. Economics of rotation and thinning revisited: the optimality of clearcuts versus continuous cover forestry. For. Policy Econ., 62, 88-94.

Tahvonen, O., Pukkala, T., Laiho, O., Lähde E. and Niinimäki, S., 2010. Optimal management of uneven-aged Norway spruce stands, For. Ecol. Manage. 260, 106-115.

Tahvonen $\mathrm{O}$ and Kallio M., 2006. Optimal harvesting of forest age classes under price uncertainty and risk aversion. Nat. Res. Mod. 19, 557-586.

Tahvonen O, Salo S and Kuuluvainen J., 2001. Optimal forest rotation and land values under a borrowing constraint. J. of Econ. Dyn. and Control 25, 1595-1627.

Wikberg, P.-E., 2004. Occurrence, morphology and growth of understory saplings in Swedish forests. Acta Universitatis Agriculturae Suecica, Silvestria 322. 
Table 1: Size class-specific parameter values

\begin{tabular}{l|llllll}
\hline $\begin{array}{l}\text { Size } \\
\text { class }\end{array}$ & $\gamma_{s}$ & $d_{s}$ & $v_{1 s}$ & $v_{2 s}$ & $v_{1 s}$ & $v_{2 s}$ \\
& & & $S I=11 m$ & $S I=11 m$ & $S I=15 m, 17 m$ & $S I=15 m, 17 m$ \\
\hline 1 & 0.0044 & 75 & 0.013 & 0 & 0.014 & 0 \\
2 & 0.0123 & 125 & 0.061 & 0 & 0.067 & 0 \\
3 & 0.0241 & 175 & 0.151 & 0 & 0.167 & 0 \\
4 & 0.0398 & 225 & 0.069 & 0.214 & 0.081 & 0.234 \\
5 & 0.0594 & 275 & 0.061 & 0.396 & 0.065 & 0.446 \\
6 & 0.0830 & 325 & 0.049 & 0.617 & 0.060 & 0.684 \\
7 & 0.1104 & 375 & 0.046 & 0.856 & 0.050 & 0.963 \\
8 & 0.1419 & 425 & 0.044 & 1.118 & 0.050 & 1.253 \\
9 & 0.1772 & 475 & 0.038 & 1.402 & 0.043 & 1.574 \\
10 & 0.2165 & 525 & 0.036 & 1.688 & 0.039 & 1.900 \\
11 & 0.2597 & 575 & 0.033 & 1.980 & 0.033 & 2.214 \\
12 & 0.3068 & 625 & 0.030 & 2.281 & 0.031 & 2.565 \\
\hline
\end{tabular}

Note: $\gamma_{s}$ basal area per tree $m^{2}, d_{s}$ diameter per tree $m m, v_{1 s}$ pulp volume per tree $m^{3}$, $v_{2 s}$ sawtimber volume per tree $m^{3}$.

Table 2: Parameter values for the harvesting cost functions

\begin{tabular}{c|cccccccc}
\hline$i$ & $C_{i 0}$ & $C_{i 1}$ & $C_{i 2}$ & $C_{i 3}$ & $C_{i 4}$ & $C_{i 5}$ & $C_{i 6}$ & $C_{i 7}$ \\
\hline th & 2.100 & 1.150 & 0.412 & 0.758 & 0.180 & 1.000 & 2.272 & 0.535 \\
\hline$c l$ & 2.100 & 1.000 & 0.397 & 0.758 & 0.180 & 1.000 & 1.376 & 0.393 \\
\hline
\end{tabular}

Note: Symbols, see equation (7).

Table 3. Optimal solutions without thinning,

\begin{tabular}{|c|c|c|c|c|c|c|}
\hline & Site $11 \mathrm{~m}$ & & \multicolumn{2}{|l|}{ Site $15 \mathrm{~m}$} & \multicolumn{2}{|l|}{ Site $17 \mathrm{~m}$} \\
\hline & \multicolumn{2}{|c|}{ Interest rate $1 \%$} & & & & \\
\hline Initial density $h a^{-1}$ & 1750 & 2250 & 1750 & 2250 & 1750 & 2250 \\
\hline Rotation & 80 years & 75 years & 65 years & 65 years & 60 years & 55 years \\
\hline Yield $m^{3} a^{-1} h a^{-1}$ & $4.2 \mathrm{~m}^{3}$ & $4.6 \mathrm{~m}^{3}$ & $6.4 \mathrm{~m}^{3}$ & $7.0 \mathrm{~m}^{3}$ & $7.2 \mathrm{~m}^{3}$ & $8.0 \mathrm{~m}^{3}$ \\
\hline \multirow[t]{2}{*}{ Bare land value $h a^{-1}$} & $€ 8470$ & $€ 9322$ & $€ 17066$ & $/ € 18845$ & $€ 22878$ & $€ 25333$ \\
\hline & Interest $r$ & te $4 \%$ & & & & \\
\hline Rotation & 65 years & 60 years & 55 years & 50 years & 50 years & 45 years \\
\hline Yield $m^{3} a^{-1} h a^{-1}$ & $4.3 \mathrm{~m}^{3}$ & $4.8 \mathrm{~m}^{3}$ & $6.2 \mathrm{~m}^{3}$ & $6.8 \mathrm{~m}^{3}$ & $6.7 \mathrm{~m}^{3}$ & $7.3 \mathrm{~m}^{3}$ \\
\hline Bare land value $h a^{-1}$ & $€-808$ & $€-693$ & $€ 107$ & $€ 360$ & $€ 928$ & $€ 1352$ \\
\hline
\end{tabular}

Note: Regeneration cost $w=€ 1500 \mathrm{ha}^{-1}$, natural regeneration maintained. 
Table 4: Comparison of clearcut (CC) and continuous cover solutions (CCF)

\begin{tabular}{|c|c|c|c|c|c|c|}
\hline & Site $11 \mathrm{~m}$ & & Site $15 \mathrm{~m}$ & & Site $17 \mathrm{~m}$ & \\
\hline $\begin{array}{l}\text { Objective/ } \\
\text { interest } \\
\text { rate }\end{array}$ & $\begin{array}{l}\text { Output }^{1} \\
\text { CC/CCF }\end{array}$ & $\begin{array}{l}\text { Rotation } \\
\text { years }\end{array}$ & $\begin{array}{l}\text { Output }^{1} \\
\text { CC/CCF }\end{array}$ & $\begin{array}{l}\text { Rotation } \\
\text { Years }\end{array}$ & $\begin{array}{l}\text { Output }^{1} \\
\text { CC/CCF }\end{array}$ & $\begin{array}{l}\text { Rotation } \\
\text { years }\end{array}$ \\
\hline MSY & $4.8 / 4.3$ & 135 & $7.5 / 6.1$ & 110 & $9.0 / 7.0$ & 90 \\
\hline $1 \%$ & $4.5 / 3.7$ & 170 & $7.1 / 6.1$ & 145 & $8.6 / 7.0$ & 115 \\
\hline $2 \%$ & $-/ 3.3$ & $\infty$ & $-/ 5.6$ & $\infty$ & $8.4 / 6.3$ & 120 \\
\hline $3 \%$ & $-/ 3.1$ & $\infty$ & $-/ 4.7$ & $\infty$ & $-/ 6.1$ & $\infty$ \\
\hline $4 \%$ & $-/ 3.0$ & $\infty$ & $-/ 4.5$ & $\infty$ & $-/ 5.1$ & $\infty$ \\
\hline
\end{tabular}

Note: ${ }^{1}$ Unit, $m^{3} a^{-1} h a^{-1}, \mathrm{w}=€ 1000, x_{10}=1750$

Table 5: Bare land values for the clearcut and continuous cover solutions when the initial number of trees is $1750\left(=x_{10}\right)$

\begin{tabular}{|c|c|c|c|c|c|}
\hline \multicolumn{6}{|c|}{ Site $11 m$} \\
\hline $\mathrm{r} / \mathrm{w}$ & $€ 0$ & $€ 500$ & $€ 1000$ & $€ 1500$ & $€ 2000$ \\
\hline $4 \%$ & $-/ 1066^{1}$ & $-/ 566$ & $-/ 189^{2}$ & $-/ 189^{2}$ & $-/ 189^{2}$ \\
\hline $3 \%$ & $-/ 2126$ & $-/ 1626$ & $-/ 1126$ & $-/ 626$ & $-/ 126$ \\
\hline $2 \%$ & $4730 / 4723$ & $-/ 4223$ & $-/ 3723$ & $-/ 3223$ & $-/ 1723$ \\
\hline $1 \%$ & $14042 / 13795$ & $13492 / 13295$ & $12816 / 12795$ & $-/ 12295$ & $-/ 11795$ \\
\hline \multicolumn{6}{|c|}{ Site $15 m$} \\
\hline $4 \%$ & $-/ 2250$ & $-/ 1750$ & $-/ 1250$ & $-/ 750$ & $-/ 250$ \\
\hline $3 \%$ & $-/ 4148$ & $-/ 3641$ & $-/ 3141$ & $-/ 2641$ & $-/ 2141$ \\
\hline $2 \%$ & $8661 / 8623$ & $8129 / 8123$ & $-/ 7623$ & $-/ 7123$ & $-/ 6623$ \\
\hline $1 \%$ & $24510 / 23646$ & $23808 / 23146$ & $23129 / 22646$ & $22495 / 22146$ & $22510 / 21646$ \\
\hline \multicolumn{6}{|c|}{ Site $17 m$} \\
\hline $4 \%$ & $3238 / 3233$ & $2733 /$ & $-/ 1731$ & $-/ 1731$ & $-/ 1231$ \\
\hline $3 \%$ & $5677 / 5638$ & $5150 / 5138$ & $-/ 4638$ & $-/ 4138$ & $-/ 3638$ \\
\hline $2 \%$ & $11374 / 11189$ & $10817 / 10689$ & $10266 / 10189$ & $9715 / 9689$ & $9192 / 9189$ \\
\hline $1 \%$ & $30650 / 28902$ & $29878 / 28402$ & $29118 / 27902$ & $28390 / 27402$ & $27687 / 26902$ \\
\hline
\end{tabular}

${ }^{1}$ Unit, $€ \mathrm{ha}^{-1} \cdot{ }^{2}$ Artificial regeneration not optimal.

Note: $r=$ interest rate, $w=$ cost of artificial regeneration. The first figure (if it exists) refers to solutions with clearcuts and the second to continuous cover solutions 
Table 6: Bare land values for the clearcut and continuous cover solutions when the initial number of trees is $2250\left(=x_{10}\right)$.

\begin{tabular}{|c|c|c|c|c|c|}
\hline \multicolumn{6}{|c|}{ Site $11 m$} \\
\hline $\mathrm{r} / \mathrm{w}$ & $€ 0$ & $€ 500$ & $€ 1000$ & $€ 1500$ & $€ 2000$ \\
\hline $4 \%$ & $-/ 1260^{1}$ & $-/ 760$ & $-/ 260$ & $-/ 189^{2}$ & $-/ 189^{2}$ \\
\hline $3 \%$ & $2473 / 2469$ & $-/ 1969$ & $-/ 1469$ & $-/ 969$ & $-/ 469$ \\
\hline $2 \%$ & $5390 / 5358$ & $4866 / 4858$ & $-/ 4358$ & $-/ 3858$ & $-/ 3358$ \\
\hline $1 \%$ & $15571 / 15033$ & $14936 / 14533$ & $14316 / 14033$ & $13701 / 13533$ & $13088 / 13033$ \\
\hline \multicolumn{6}{|c|}{ Site $15 m$} \\
\hline $4 \%$ & $2679 / 2662$ & $-/ 2162$ & $-/ 1662$ & $-/ 1162$ & $-/ 662$ \\
\hline $3 \%$ & $4819 / 4798$ & $4302 / 4298$ & $3798 /$ & $-/ 3298$ & $-/ 2798$ \\
\hline $2 \%$ & $9866 / 9730$ & $9319 / 9230$ & $8778 / 8730$ & $8246 / 8230$ & $-/ 7730$ \\
\hline $1 \%$ & $27154 / 25591$ & $26443 / 25091$ & $25746 / 24591$ & $25061 / 24091$ & $24385 / 24091$ \\
\hline \multicolumn{6}{|c|}{ Site $17 m$} \\
\hline $4 \%$ & $3854 / 3790$ & $3340 / 3290$ & $2834 / 2790$ & $2332 / 2290$ & $1827 / 1790$ \\
\hline $3 \%$ & $6604 / 6501$ & $6063 / 6001$ & $5540 / 5501$ & $5020 / 5001$ & $4507 / 4501$ \\
\hline $2 \%$ & $12957 / 12546$ & $12360 / 12146$ & $11789 / 11546$ & $11224 / 11146$ & $10668 / 10546$ \\
\hline $1 \%$ & $34183 / 31307$ & $33365 / 30807$ & $32548 / 30307$ & $31765 / 29807$ & $31000 / 29307$ \\
\hline
\end{tabular}

${ }^{1}$ Unit, $€$ ha $^{-1} .{ }^{2}$ Artificial regeneration not optimal.

Note: $r=$ interest rate, $w=$ cost of artificial regeneration. The first figure (if it exists) refers to solutions with clearcuts and the second to continuous cover solutions 
Figure captions

Figure 1a,b: Properties of variable harvesting cost functions

Note: In Figure b, $\sum_{s=1}^{n} h_{s}=1$.

Figure 2a,b. Development of stand volume and clearcut value without thinning

Note: natural regeneration is included

Figure 3a,b: Bare land value with different rotation periods

Note: Site index $S I=17, r=0.03, x_{10}=1750, w=0$ in (a), $w=1500$ in (b)

Figures $4 \mathrm{a}-\mathrm{d}$. Development of post-harvest stand volumes and number of trees under optimal continuous cover solutions

Note: Site index 17, $x_{10}=1750$

a) $r=0.01$, size of harvested trees $325-475 \mathrm{~mm}$

b) $r=0.02$, size of harvested trees $275-425 \mathrm{~mm}$

c) $r=0.03$, size of harvested trees $275-375 \mathrm{~mm}$

d) $r=0.04$, size of harvested trees $225-375 \mathrm{~mm}$

Figure 5: Optimal stand structure over the steady-state cycle

Note: Site index 17, $r=0.02$.

Figure 6a-d: Development of stand volume and number of trees in optimal clearcut solutions.

Note: Site $17 m, x_{10}=1750, \mathrm{w}=0$, a) $\left.\left.\mathrm{r}=0.01, \mathrm{~b}\right) \mathrm{r}=0.02, \mathrm{c}\right) \mathrm{r}=0.03$, d) $\mathrm{r}=$ 0.04 


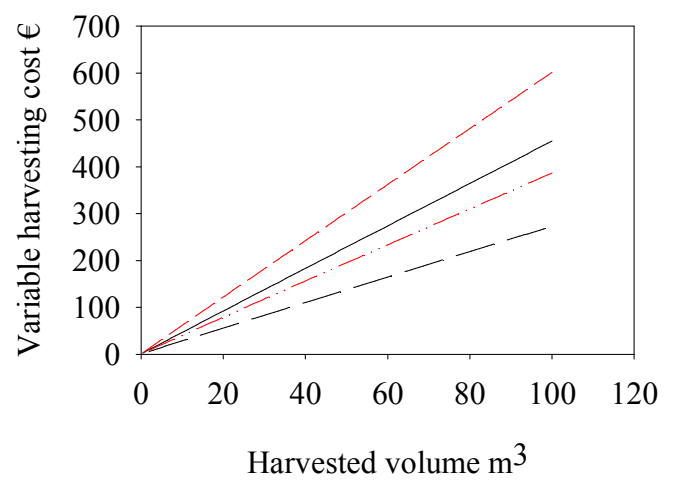

Clearcut $\mathrm{v}=0.5 \mathrm{~m}^{3}$

- C Clearcut $\mathrm{v}=2 \mathrm{~m}^{3}$

- Continus cover harvesting $\mathrm{v}=0.5 \mathrm{~m}^{3}$

-.....- Continuous cover harvesting $\mathrm{v}=2 \mathrm{~m}^{3}$ b

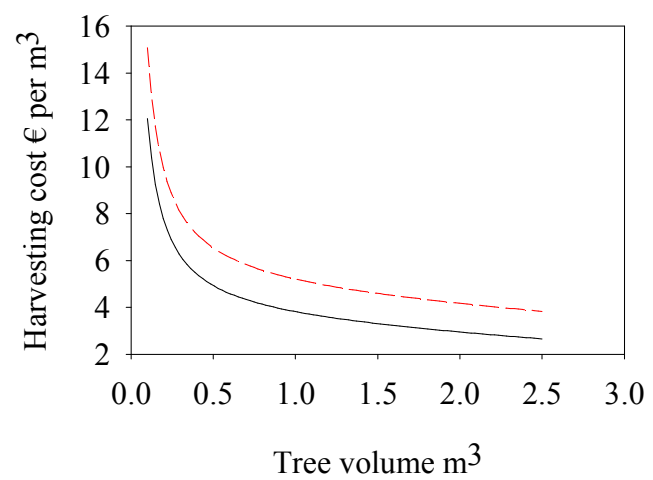

Clearcut

- - Continuous harvesting

Figure 1a,b: Properties of variable harvesting cost functions

Note: In Figure b, $\sum_{s=1}^{n} h_{s}=1$. 
(a)

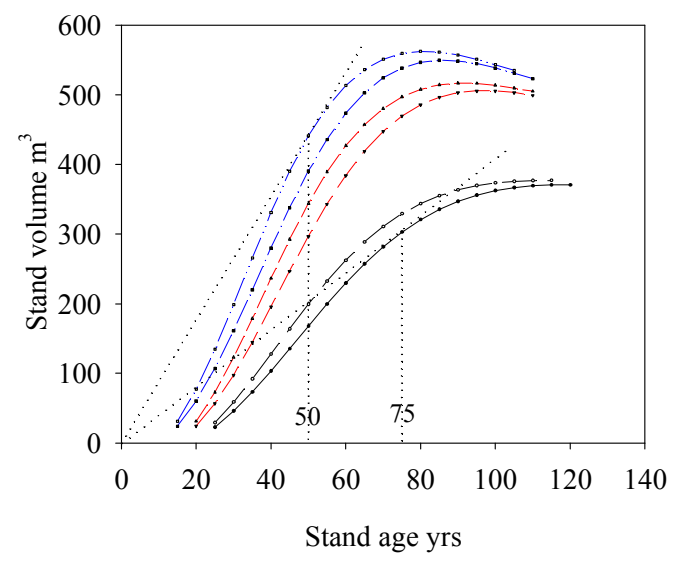

$\begin{array}{lll}\longrightarrow & \mathrm{SI}=11 \mathrm{~m}, x_{10}=1750 & \ldots \ldots-\cdots \\ -\cdots & \mathrm{SI}=11 \mathrm{~m}, x_{10}=2250 & \ldots \cdots \\ -\ldots & \mathrm{SI}=15 \mathrm{~m}, x_{10}=1750 & \ldots \cdots \cdots\end{array}$ (b)

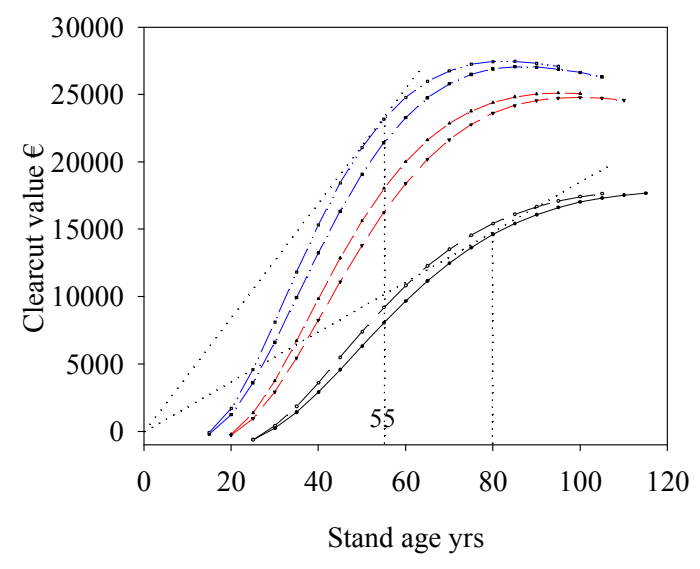

$\mathrm{SI}=15 \mathrm{~m}, x_{10}=2250$

$\mathrm{SI}=17 m, x_{10}=1750$

$\mathrm{SI}=17 \mathrm{~m}, x_{10}=2250$

Figure 2a,b. Development of stand volume and clearcut value without thinning Note: natural regeneration is included 
a

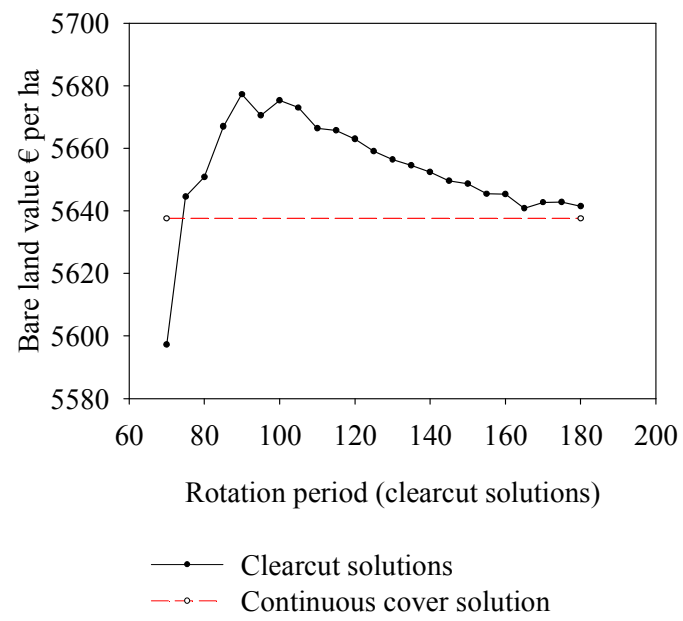

b

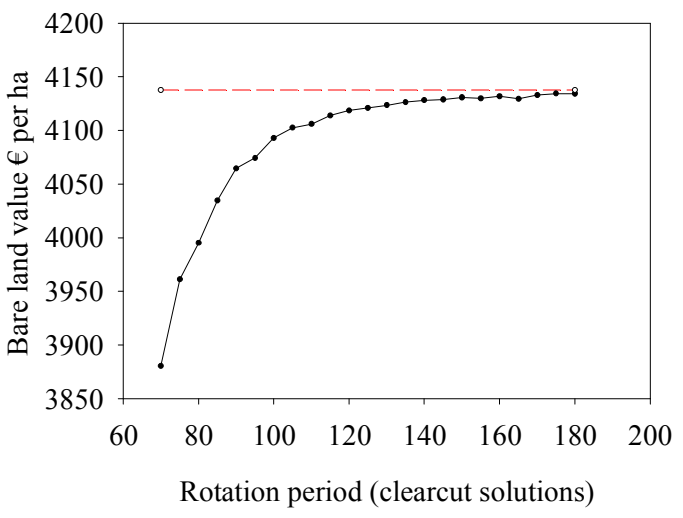

Figure 3a,b: Bare land value with different rotation periods

Note: Site index $S I=17, r=0.03, x_{10}=1750, w=0$ in (a), $w=1500$ in (b) 
a

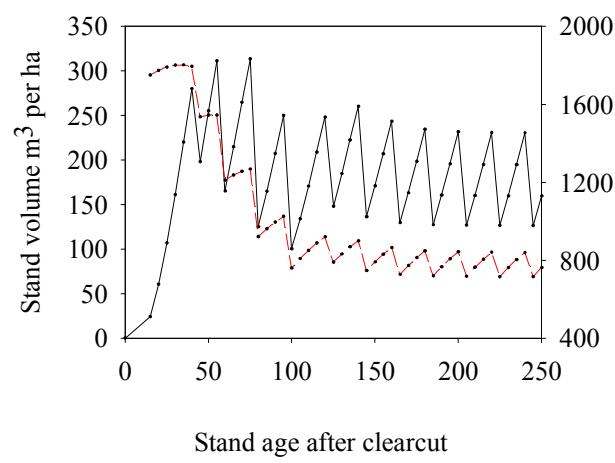

c

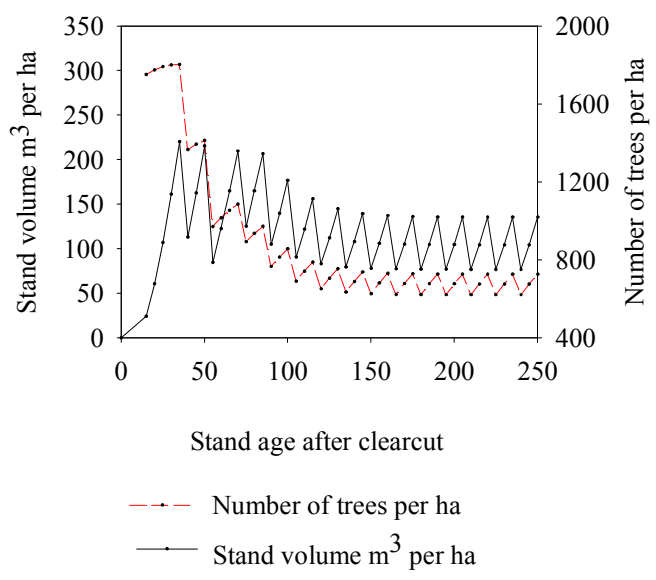

b

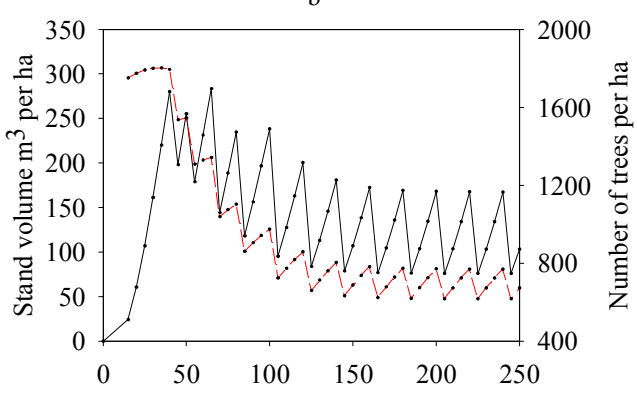

Stand age after clearcut

d

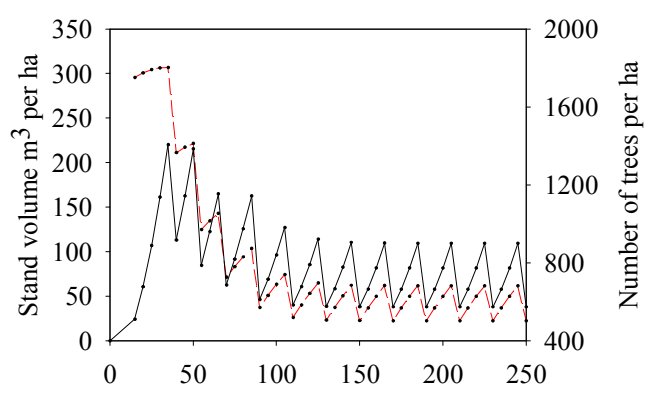

Stand age after clearcut

Figures 4a-d. Development of post-harvest stand volumes and number of trees under optimal continuous cover solutions

Note: Site index 17, $x_{10}=1750$

a) $r=0.01$, size of harvested trees $325-475 \mathrm{~mm}$

b) $r=0.02$, size of harvested trees $275-425 \mathrm{~mm}$

c) $r=0.03$, size of harvested trees $275-375 \mathrm{~mm}$

d) $r=0.04$, size of harvested trees $225-375 \mathrm{~mm}$ 


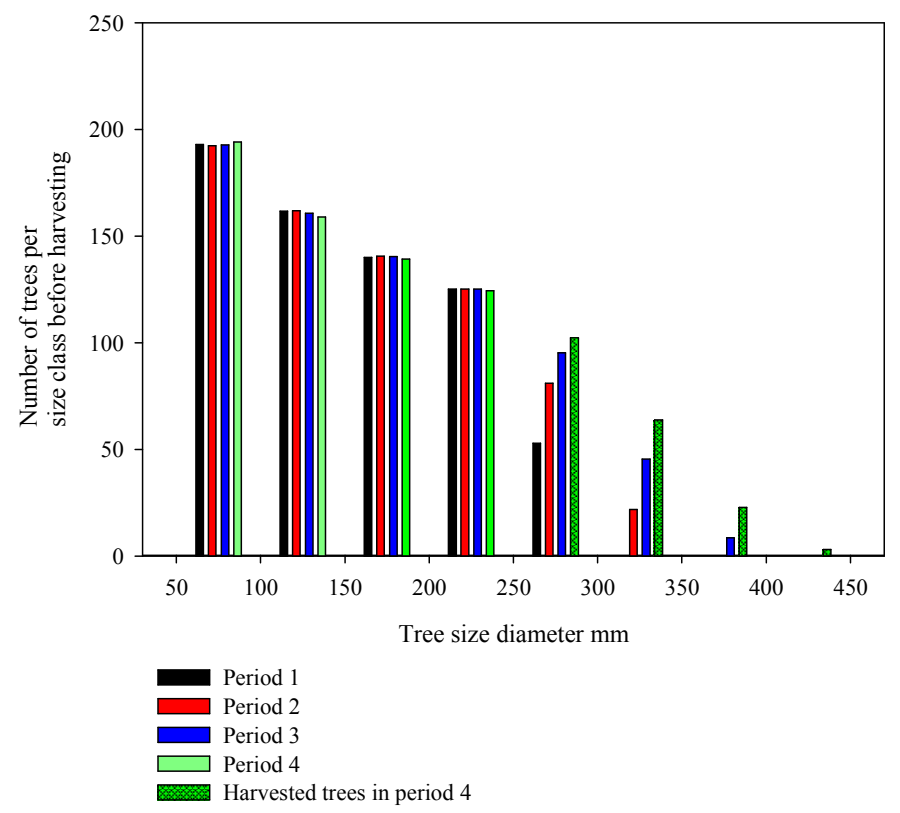

Figure 5: Optimal stand structure over the steady-state cycle.

Note: Site index 17, $r=0.02$. 

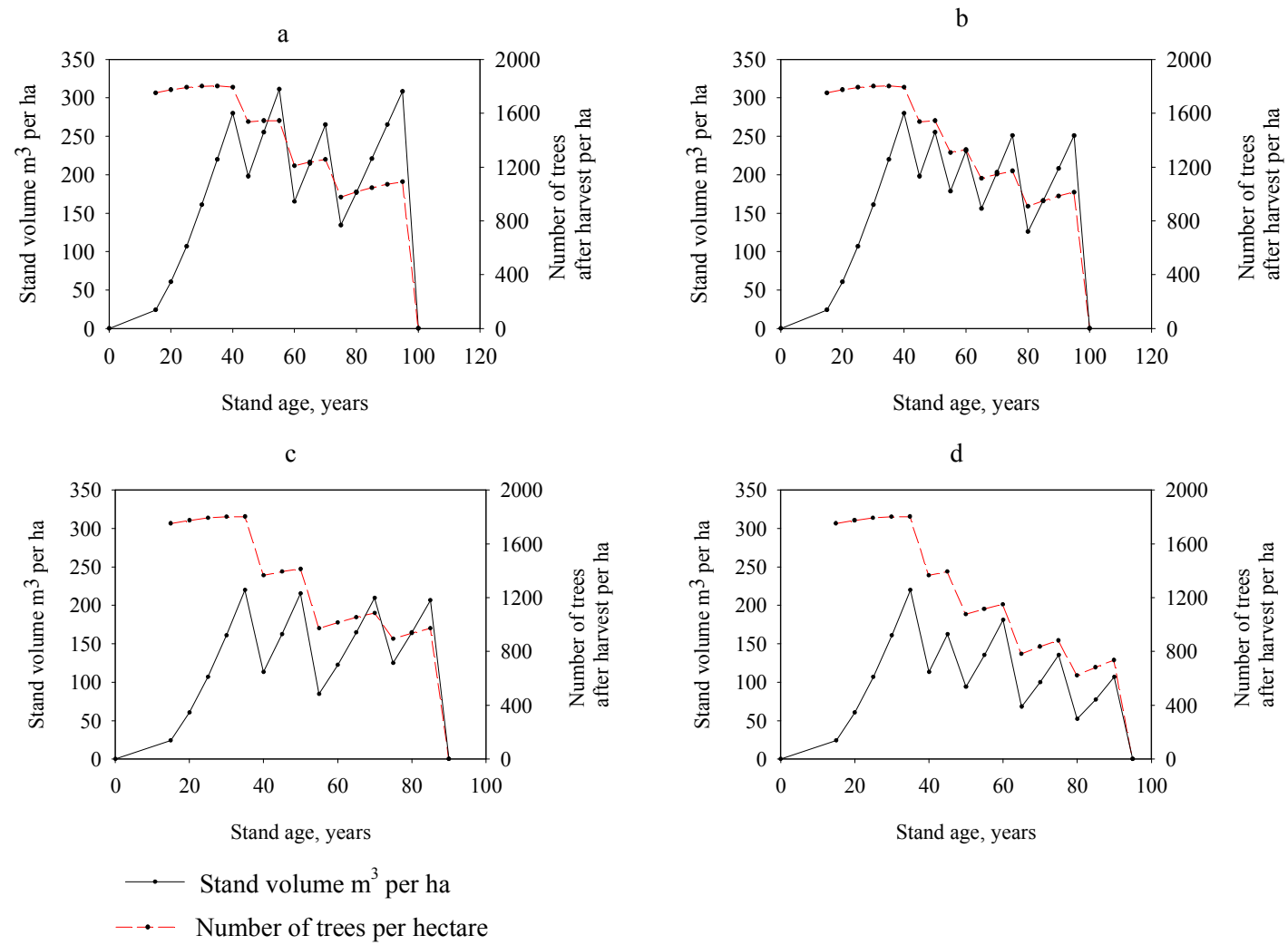

Figure 6a-d: Development of stand volume and number of trees in optimal clearcut solutions.

Note: Site $\left.\left.17 m, x_{10}=1750, w=0, a\right) r=0.01, b\right) r=0.02$, c) $r=0.03$, d) $r=0.04$ 